\title{
FEMALE MONOGAMY AND MALE COMPETITION IN PHOTINUS COLLUSTRANS (COLEOPTERA: LAMPYRIDAE)*
}

\author{
By Steven R. Wing \\ Department of Entomology and Nematology \\ University of Florida \\ Gainesville, Florida 32611
}

\section{INTRODUCTION}

Matings by Photinus collustrans females can easily be kept track of in the field. These brachypterous females live in burrows and remain near them. About 20 minutes after sunset males start to fly and search for females, which take positions on the soil surface or on vegetation (Lloyd 1966). Females flash in response to the signals of flying males, which locate them by their responses. Each night sexual activity is restricted to a period about 18 minutes long (Lloyd 1966; also see T. Walker 1983 for a discussion of such 'sprees'). $P$. collustrans females live about 10 days after their first appearance (Wing 1982); by observing a female for about 20 minutes per night for 10 nights, every sexual activity of her life can be recorded. There is no evidence that females mate under circumstances other than those mentioned above.

This field study shows that only a very small proportion of collustrans females mate more than once. Yet the potential for female multiple mating apparently is the basis for the evolution of a complex of tactics used by competing males.

\section{Methods AND Materials}

Field studies of collustrans were conducted in Alachua County, Florida. The site was a grassy area under scattered oaks, pines, and shrubs. The grass was mowed periodically. Two streetlights illuminated parts of the site.

Females were located by their flash and/or glow responses to penlight simulations of male mating signals (see Lloyd 1966). The location of each female was marked by placing a numbered flag about $15 \mathrm{~cm}$ to the north of her. Flags were $10 \times 40 \mathrm{~cm}$ strips of

*Manuscript received by the editor January 22, 1984. 
plastic held in place with nails. Females use the same burrow throughout their adult lives (Wing 1982), and numbered flags placed at the burrow location were sufficient to identify each individual. Copulations were timed with a stopwatch, and some were observed with a magnifying glass.

An $18 \times 20 \mathrm{~m}$ area was searched for females nightly starting before male flights began and ending after they had ended for the night. The location of each female was marked and I inspected her position at approximately $1 \mathrm{~min}$ intervals.

Each time a female's position was visited on a given night, she was presented penlight simulations of the male signal. Because females do not respond following a successful mating, but pause and then re-enter their burrow (Wing 1982), a female answer to my signal indicated that she was not yet mated. If she failed to respond, I determined whether she was 1) still out but not responsive; 2) mating; 3) entering her burrow; or 4) gone. All female locations were checked until the adult season was over.

Because the same area was searched nightly throughout the season, when a new female appeared she was almost certainly a virgin making her first appearance. Complete sexual histories of 108 collustrans females were recorded.

\section{RESULTS}

Of the 108 females whose complete sexual histories were determined, 104 mated only once. The general sexual pattern was as follows. The female appeared by her burrow nightly until she attracted a male ( $\overline{\mathrm{x}}=2$ nights). The male, having located the female by her continued responses to his signals, landed nearby and walked to her. Upon making physical contact, the male climbed upon the female, and copulated with her in the male-above position (Fig. 1). Copulation lasted about 1 min (details below). The male broke the connection, dismounted, and flew away leaving the female outside her burrow. Following copulation the female paused for seconds or minutes, and did not flash responses to signals of passing males. She then entered her burrow.

\footnotetext{
'During this study 91 females were individually marked with Tech Pen Ink dispensed from Hamilton's paint pots (T. Walker and Wineriter 1981). Females appeared for up to 10 consecutive nights. Every appearance by each marked female occurred at her original position.
} 
Four females mated more than once. One of these females was dug from her burrow by a male, one was mated by a "sneaky" male, and two made themselves available to males by their own behavior.

The two repeated matings due to female behavior occurred when females mated and entered their burrows, but on subsequent nights left their burrows, responded to male signals, and mated again. Only three of 108 females appeared on nights subsequent to the first mating. Two mated again; one remated once, the other twice.

When more than one male landed at a responding female, the first male to reach her mounted and began copulation. The rival male attempted to mount the female (sometimes backwards), and to break the pair apart (Fig. 2). As a result, the copulating male moved or was pushed off the female and copulations proceeded in the tailto-tail position, and variations thereof. (In the tail-to-tail position the male and female face in opposite directions while maintaining genitalic connection. Due to disturbance by rival males, pairs were sometimes moved into odd positions, even with the female on the copulating male's dorsum.)

Copulations were significantly longer when rival males were present. Mean duration for single male copulations was $57 \mathrm{sec}$ $(\mathrm{n}=23$, range $30-185 \mathrm{sec})$ compared to $842 \mathrm{sec}(\mathrm{n}=5$, range 339-1410 sec) Mann-Whitney $(\mathrm{U}=115) \mathrm{P}<.0005$ when rivals were present. In these cases, copulating males maintained the genital connection until after the females had entered their burrow (Fig. 3). Females entered head first, dragging the coupled males backwards down the burrow. In one case, only the head and thorax of the male remained outside the burrow when the genital connection was broken. After disengaging, males climbed out and flew away. After the mated male departed, in four of seven cases the rival male tried to remove the female from her burrow. Rival males located the burrow opening by antennating the soil. Rivals dug at the burrow (Fig. 4), sometimes completely entering it. On one occasion the male succeeded in removing the female from her burrow and mated with her (this accounted for the third multiple mating) (Fig. 5). Unsuccessful males dug for as long as $35 \mathrm{~min}$ before leaving.

The fourth repeated mating resulted from another behavior of rival males and was observed once during this study and once since then. The rival "sneaky" male was non-aggressive, and made only occasional contact with the copulating pair. The rival gently antennated the pair and then walked away, returned and antennated 

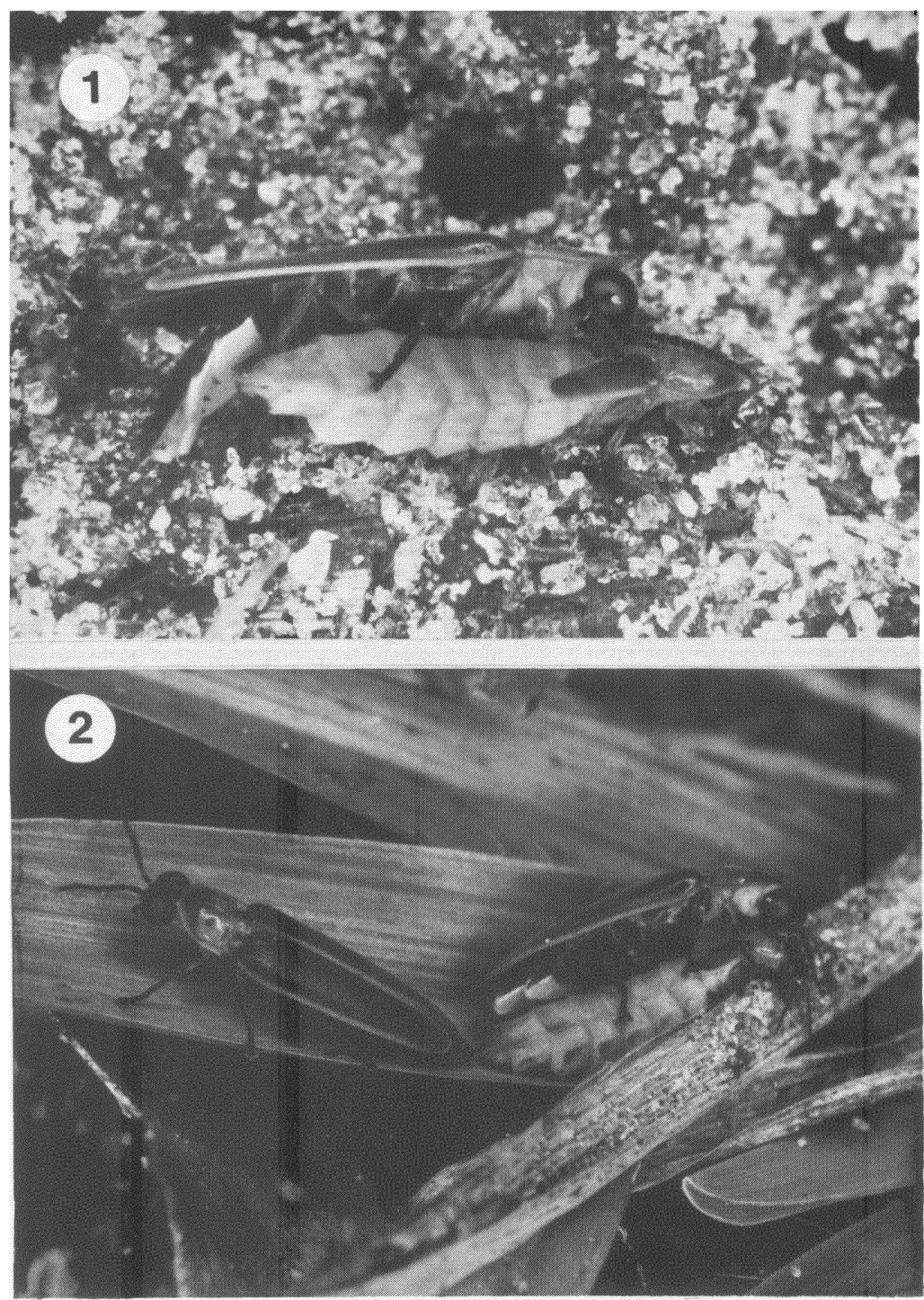

Fig. 1. Photinus collustrans male (above) mounting female. Note burrow opening in background. The female is about $11 \mathrm{~mm}$ long. Fig. 2. Photinus collustrans trio. Male on left is copulating. Rival has mounted female. 

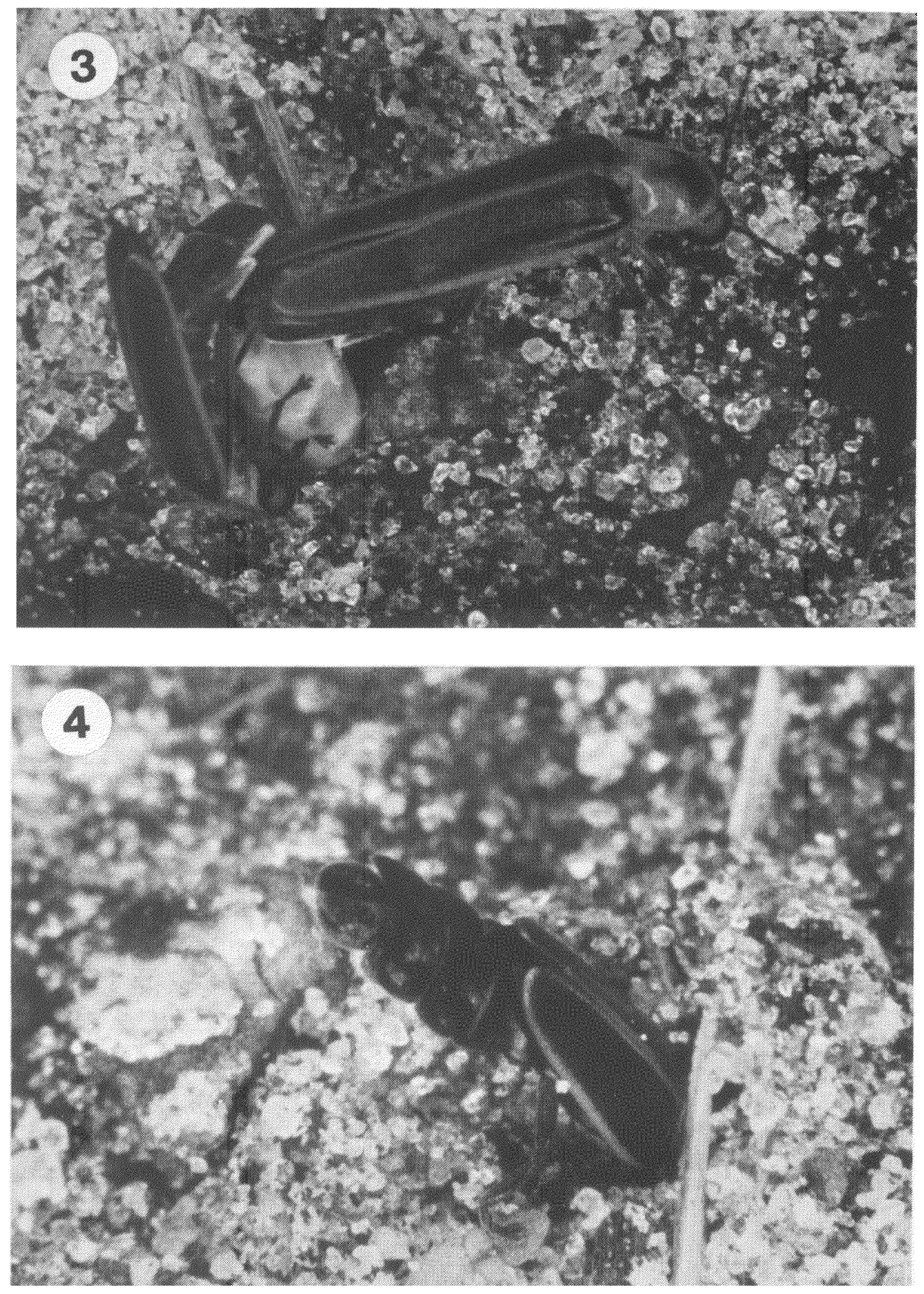

Fig. 3. Rival male (left) remains mounted as female enters burrow. Male on right is copulating. Fig. 4. Rival male digs at female's burrow. 
again. The copulating male stayed in the male-above position, and copulation was not prolonged. After copulation, the male dismounted and flew away, leaving the female outside her burrow. The rival male then located the female and mated with her.

\section{Discussion}

Females are difficult for males to locate (Lloyd 1979). With a period of only about $18 \mathrm{~min}$ nightly to operate in, the usual male strategy after finding a female is to mate and, within a minute or so, return to the air searching for another female.

Females pause after mating, but do not answer the flashes of passing males. They then enter the burrow. Less than $3 \%$ of the females that mated ever made themselves available to males again (also see Wiklund 1982), and those that did may have had some fault in the mechanism that indicates whether sufficient sperm was acquired (also see W. Walker 1980).

During the pause before re-entering the burrow females are susceptible to another mating if found. Even after re-entering the burrow a female may be dug up and remated. Generally, then, if a male can gain physical access to a female, he can mate with her. The fact that an accessible female could be mated if found has led to prolonged copulation when a rival male is present (Parker 1970). Copulating males make the female physically unavailable by occupying her until she has returned to her burrow (see Sivinski 1983). Rival males try to break the coupled pair apart and attempt to gain access to the female by digging her from the burrow. The "sneaky" rival avoids triggering mate-guarding by the coupled male, and thereby gains access to the female after her first mate leaves.

The frequency of male encounters with rivals might vary with male density, but the overall proportion of females that mate repeatedly is probably rarely if ever much greater than the four per hundred found in this study. ${ }^{2}$ The complex of male strategies and counter-strategies shown here reflects how important the potential for female multiple mating can be, even when only a small proportion of females actually mate more than once.

\footnotetext{
${ }^{2}$ Based on 71 matings observed when male density was at a 3-year peak (Wing unpublished data). It should also be noted that mated females are sometimes flooded from their burrows, and may remate under these circumstances (Wing 1982 and unpublished).
} 


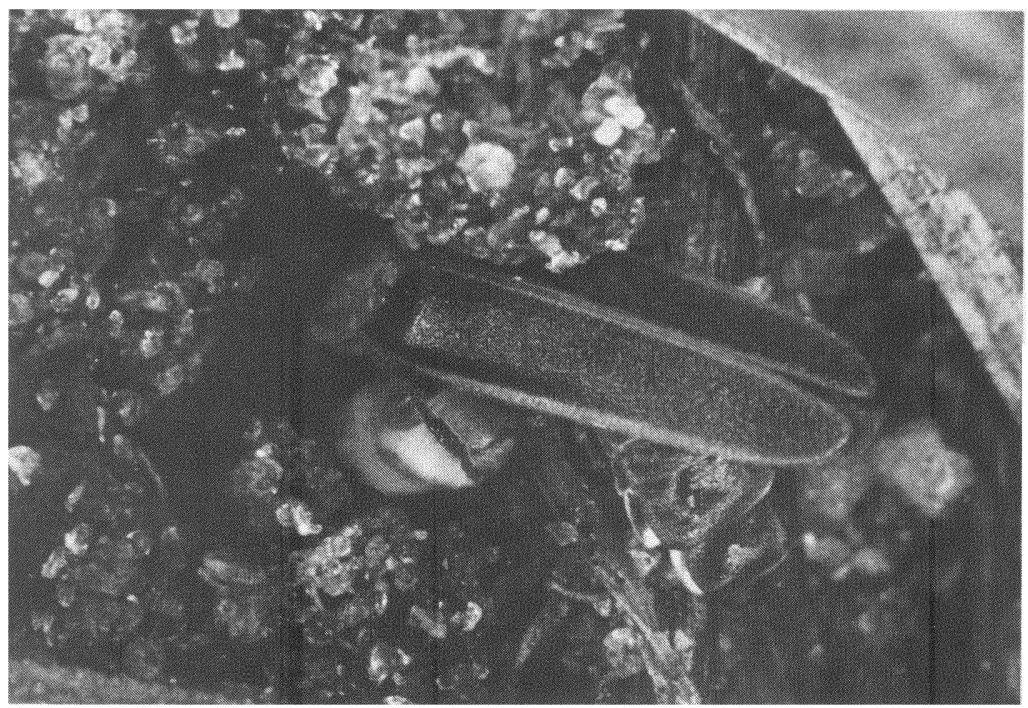

Fig. 5. Rival male pulls female from her burrow.

\section{SumMary}

Four of 108 Photinus collustrans females mated more than once. One was dug from her burrow by a male, one was mated by a "sneaky" male, and two made themselves available to males after mating.

\section{ACKNOWLEDGMENTS}

The photograph for Fig. 2 was made by T. G. Forrest. J. E. Lloyd introduced me to fireflies and reviewed the manuscript several times. Reviews by T. G. Forrest and J. Sivinski also improved the paper. Special thanks for comments by members of the Editorial Board at Psyche. Barbara Hollien typed the manuscript. S. A. Wineriter helped mount the photographs. Some of the work was funded by NSF grant no. DEB-7821744. Florida Agricultural Experiment Station Journal Series No. 4934.

\section{Literature Cited}

LLOYD, J. E.

1966. Studies on the flash communication system in Photinus fireflies. Univ. Mich. Misc. Publ. No. 130. 
1979. Sexual selection in luminescent beetles. Pages 293-342 in M. S. Blum and N. A. Blum (eds.): Sexual selection and reproductive competition in insects. Academic Press, New York.

PARKer, G. A.

1970. Sperm competition and its evolutionary consequences in the insects. Biol. Rev. 45:525-567.

SiVINSKI, J.

1983. Predation and sperm competition in the evolution of coupling durations, particularly in the stick insect Diapheromera veliei. Pages 147-162 in D. T. Gwynne and G. K. Morris (eds.): Orthopteran mating systems: sexual competition in a diverse group of insects. Westview Press, Boulder.

WALKER, T. J.

1983. Diel patterns of calling in nocturnal Orthoptera. Pages 45-72 in D. T. Gwynne and G. K. Morris (eds.): Orthopteran mating systems: sexual competition in a diverse group of insects. Westview Press, Boulder.

WALKer, T. J., AND S. A. Wineriter.

1981. Marking techniques for recognizing individual insects. Fla. Entomol. 64:18-29.

WALKER, W. F.

1980. Sperm utilization strategies in nonsocial insects. Am. Nat. 115:780-799.

WiKLUND, C.

1982. Behavioural shift from courtship solicitation to mate avoidance in female ringlet butterflies (Aphantopus hyperanthus) after copulation. Anim. Behav. 30:790-793.

WING, S. R.

1982. Reproductive ecologies of three species of fireflies. M.S. Thesis, Univ. of Florida, Gainesville. 

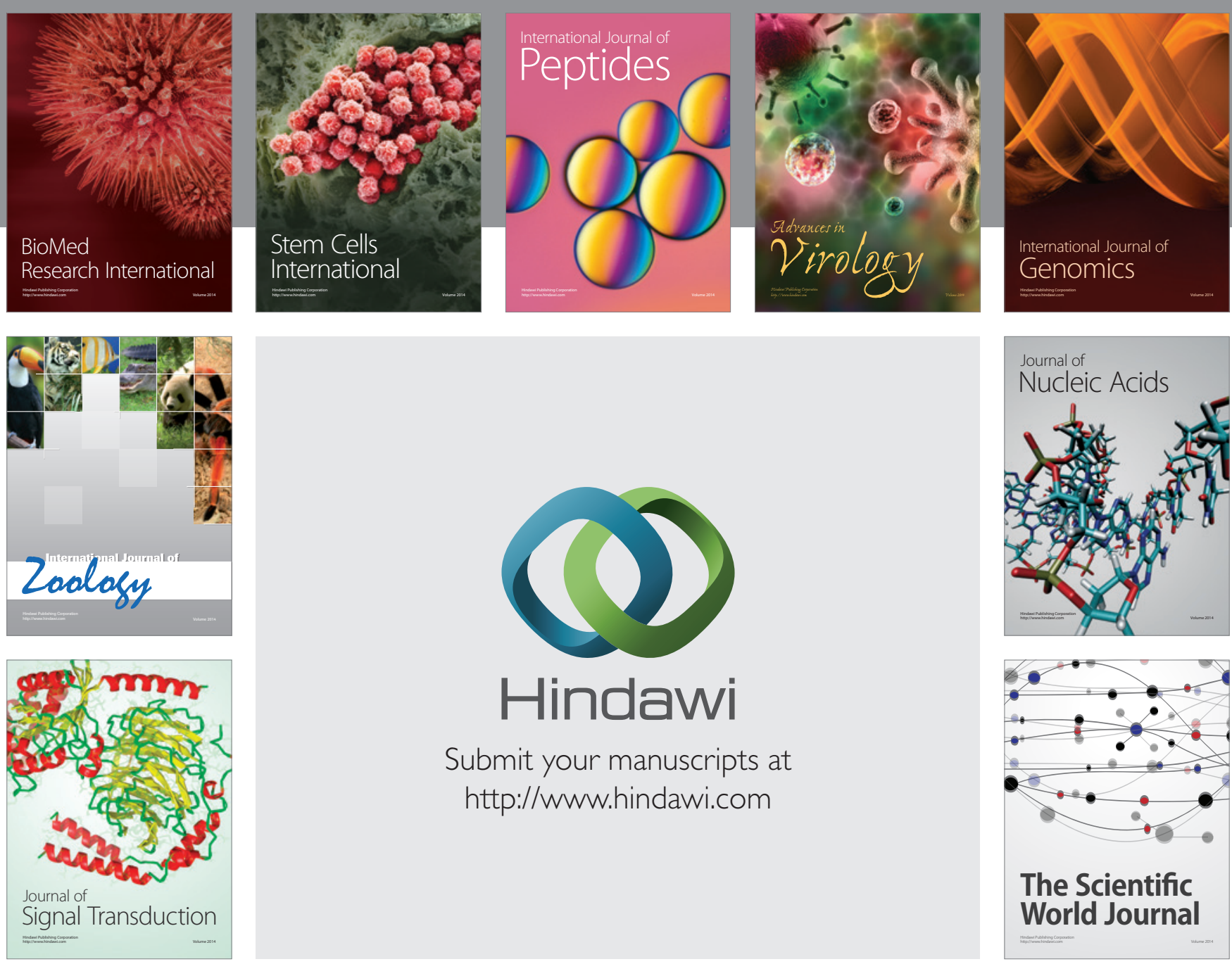

Submit your manuscripts at

http://www.hindawi.com
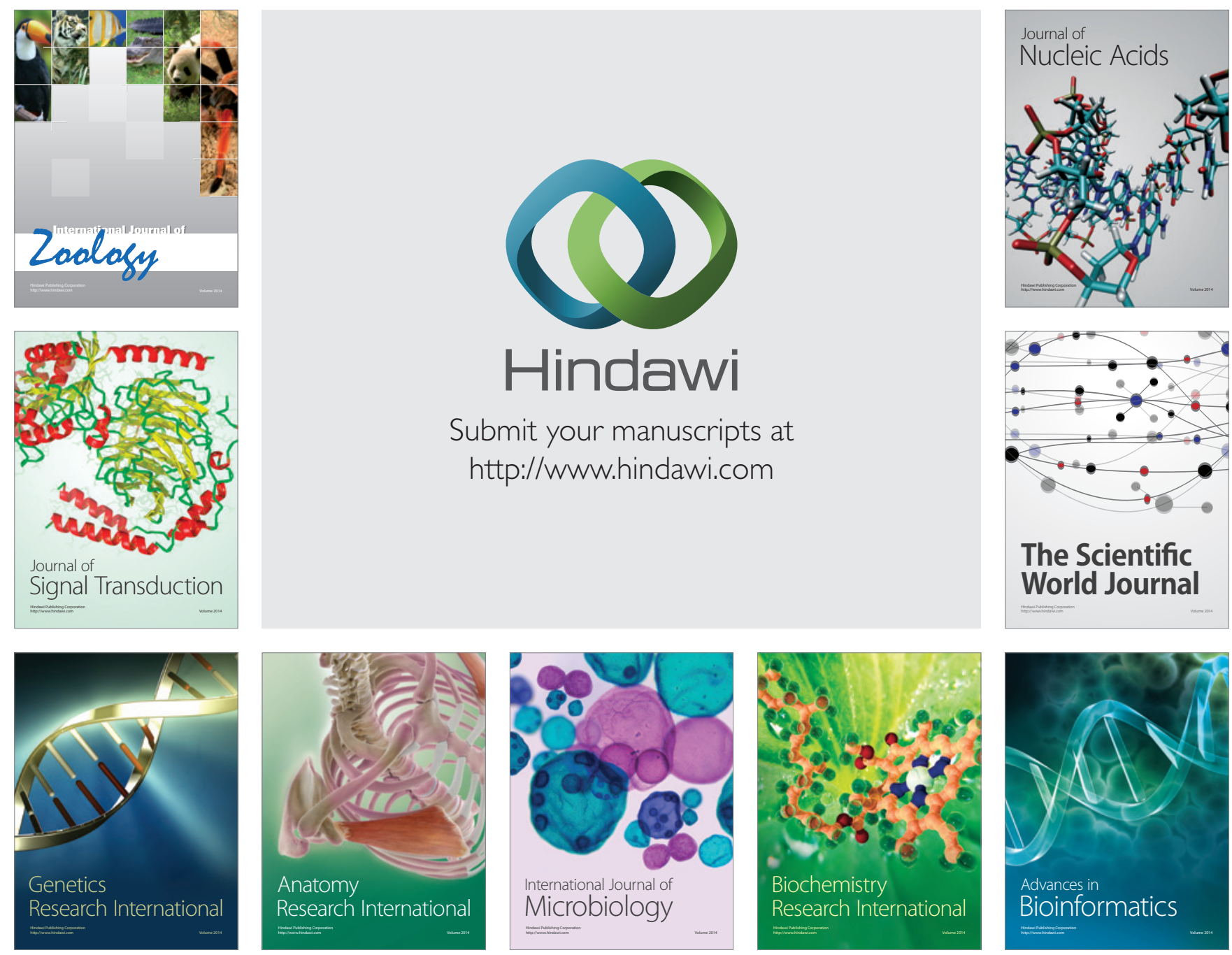

The Scientific World Journal
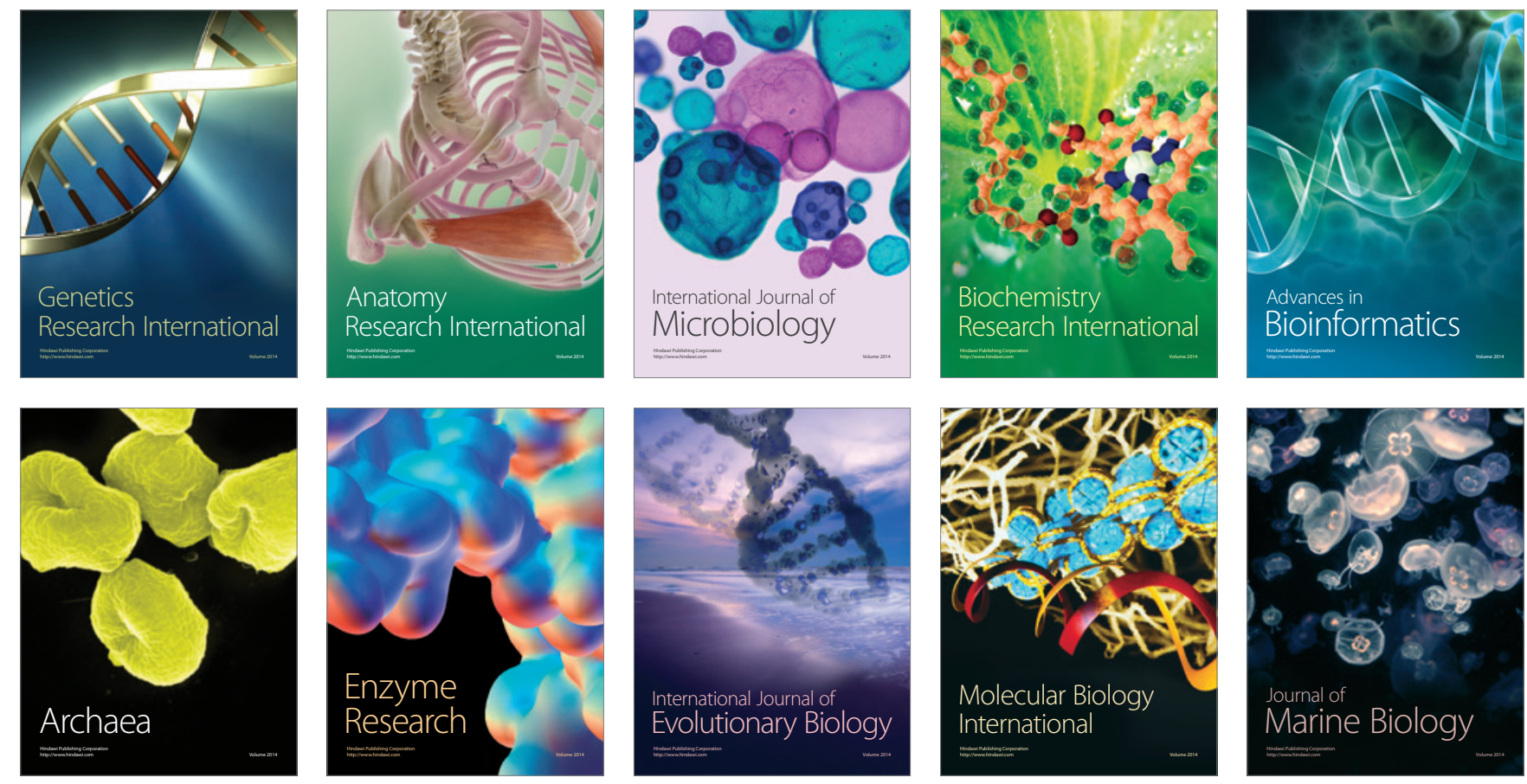